\title{
Endoscopic incision of a rectal anastomotic fistula wall following pancolectomy with ileorectal anastomosis
}

A 47-year-old woman was found to have a rectal anastomotic fistula 3 months after undergoing pancolectomy with ileorectal anastomosis and a procedure for prolapse and hemorrhoids (PPH), for slow transit constipation and rectal prolapse. The fistula ( Fig.1a-c) had two openings, both in the rectum. The proximal opening of the fistula was at the ileorectal anastomosis, $15 \mathrm{~cm}$ above the anus ( $\mathbf{F i g . 1} \mathbf{a}$ ). The distal fistula opening was at the $\mathrm{PPH}$ anastomosis staple line, $3 \mathrm{~cm}$ above the anus ( Fig.1b). Pelvic magnetic resonance imaging (MRI) showed the fistula behind the rectum at a distance of $2.2 \mathrm{~cm}$ ( Fig. 1d), with no intervening large vessels or important muscle or other organs. Laparoscopic ileostomy was done to divert the flow of stool; however, after 1 month the fistula showed little improvement. We therefore decided to attempt endoscopic incision of the entire length of the fistula to permit unobstructed drainage directly to the rectum. First, a guide wire followed by a urethral catheter was inserted into the fistula ( $\bullet$ Fig. 2a,b). Second, following the urethral catheter, the superficial layer of the rectal posterior wall was cut open slightly using electrothermal forceps and an electronic needle-knife, making an incision line ( Fig. $\mathbf{2 c}$, d). Then an insulation-tipped electrosurgical knife (IT-knife, KD-610L; Olympus, Tokyo, Japan) was placed vertically into the incision line, and used to cut open laterally the rest of the connective tissue between the rectum and the fistula, so that the urethral catheter was exposed ( Fig.2d,e). Thus, finally, the entire length of fistula was directly open to the rectum ( $\mathbf{F i g . 2 f}$ ), and the slight bleeding resolved with electrocoagulation. Follow-up colonoscopies 12 days later ( $\bullet$ Fig. $\mathbf{3 a}$ ) and 2 months later ( Fig.3b) showed a clean fistula wall with fresh granulation tissue growing well ( Fig.3b).

Anastomotic leakage is a feared complication after colorectal surgery. Traditional treatments include tube drainage and reoperation. A second operation always

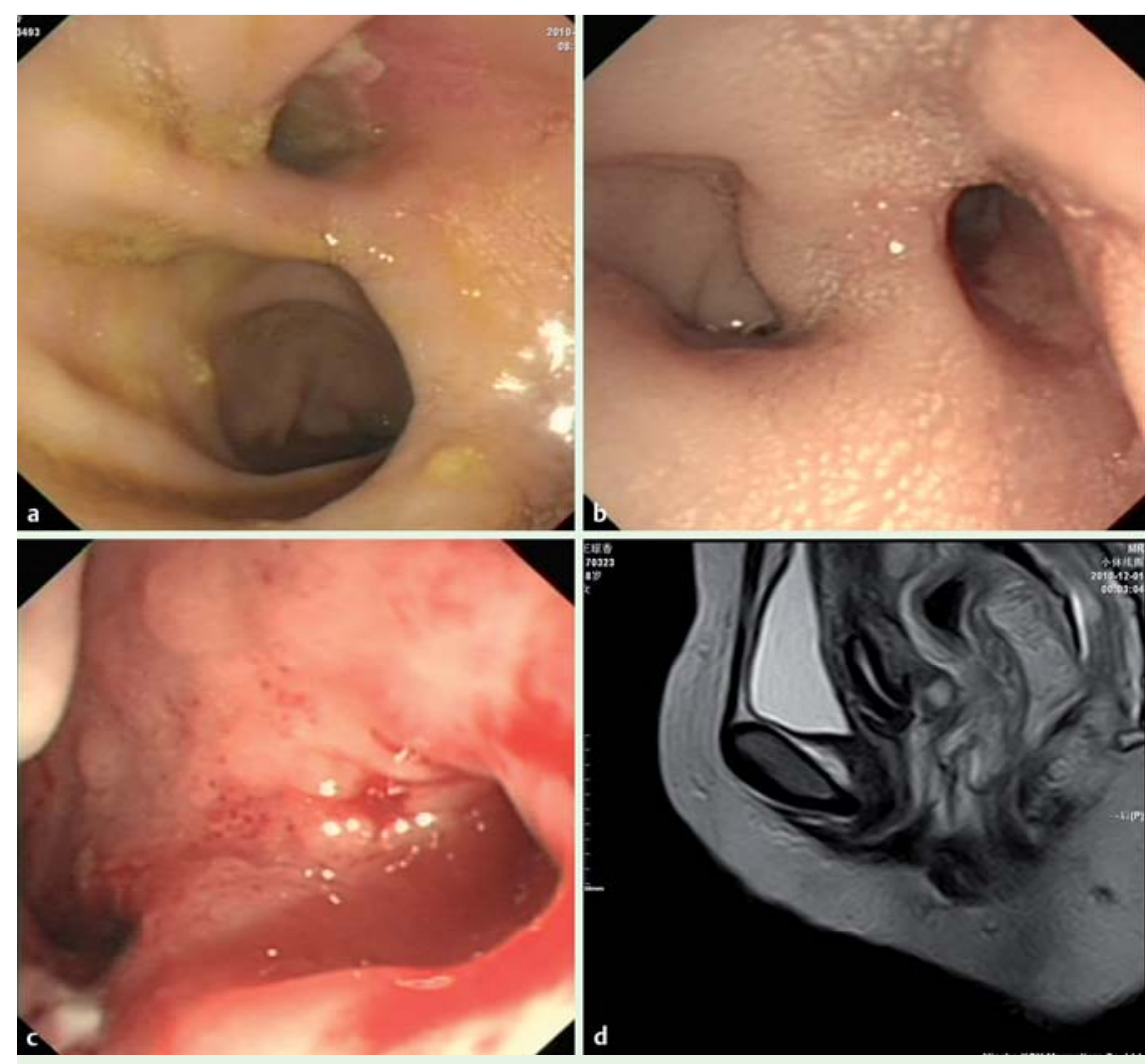

Fig. 1 Rectal anastomotic fistula following pancolectomy with ileorectal anastomosis, and procedure for prolapse and hemorrhoids (PPH) in a 47-year-old woman. a Proximal opening of the fistula. b Distal fistula opening. c Fistula membrane. d Appearance at pelvic magnetic resonance imaging (MRI).

involves ileostomy or colostomy to prevent flow of stool through the fistula. However, some long, narrow, and tortuous fistulas have been difficult to treat using only traditional methods.

Recently, there have been several reports on endoscopic treatments for gastrointestinal fistulas. Weidenhagen et al. [1] treated 29 patients with anastomotic leakages following rectal anterior resection by endoscopically assisted placement of an open-cell sponge connected to a vacuum device into the abscess cavity. Testi et al. reported successful treatment of eight anastomotic leakages following low anterior resection of the rectum by endoscopic plugging of the internal opening of the fistula with human fibrin adhesive [2].
Ibis et al. used endoclipping to achieve endoscopic closure of leakage following anterior resection of the rectum [3]. The present paper is the first to describe successful treatment of a rectal anastomotic fistula by an endoscopic incision method - which may be useful for treating fistulas located alongside the gastrointestinal tract with no intervening large vessels or important organs. Further evaluation of this approach is warranted.

Endoscopy_UCTN_Code_TTT_1AQ_2AG

Competing interests: None 


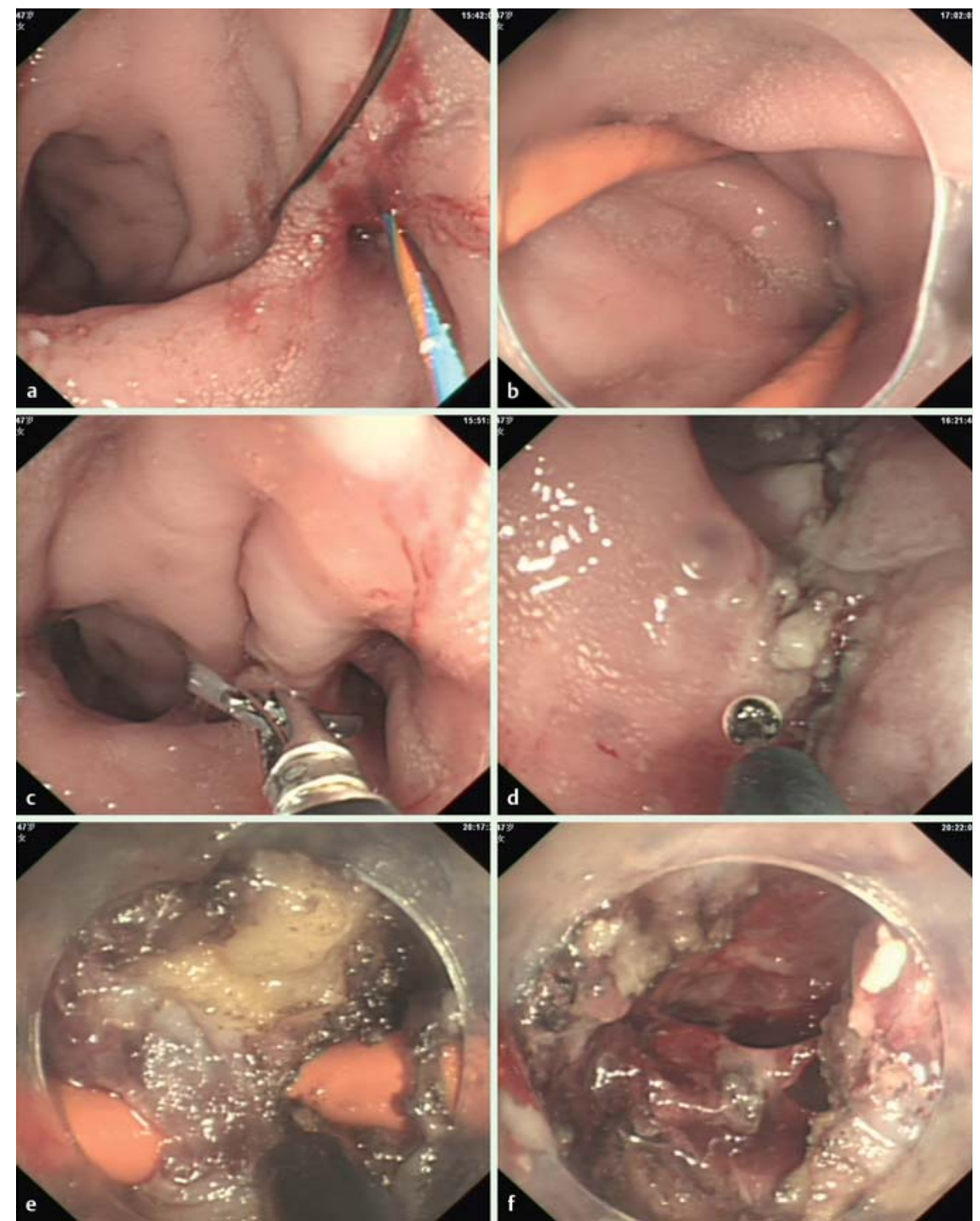

Fig. 2 a Insertion of guide wire. b Insertion of urethral catheter. c Incision of superficial rectal layer. d Incision with insulation-tipped-knife. e Incision continued until exposure of the urethral catheter. f Entire length of fistula directly open to the rectum.

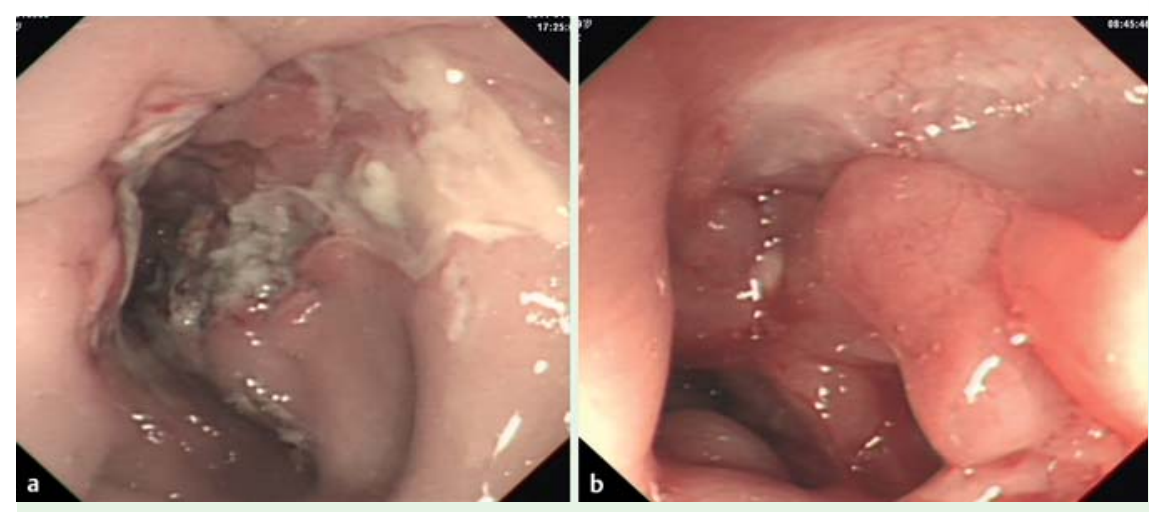

Fig. 3 Follow-up colonoscopy: a 12 days later; and $\mathbf{b} 2$ months later.

\section{Z. Liư ${ }^{1}$, C. Li ${ }^{1}$, J. Wang ${ }^{2}$, Y. Liu' ${ }^{1}$}

${ }^{1}$ Gastrointestinal Endoscopy Center, Sixth Affiliated Hospital of Sun Yat-sen University, Guangzhou, Guangdong, China

2 Division of Gastrointestinal Surgery, Sixth Affiliated Hospital of Sun Yat-sen University, Guangzhou, Guangdong, China

\section{References}

1 Weidenhagen R, Gruetzner KU, Wiecken T et al. Endoscopic vacuum-assisted closure of anastomotic leakage following anterior resection of the rectum: a new method. Surg Endosc 2008; 22: $1818-1825$

2 Testi $W$, Vernillo $R$, Spagnulo $M$ et al. Endoscopic treatment of intestinal anastomotic leakage in low anterior resection of the rectum by using fibrin adhesive. Our experience. Minerva Chir 2002; 57: 683-688

3 Ibis M, Beyazit Y, Onal IK et al. Successful endoscopic closure of anastomotic leakage following anterior resection of the rectum by endoclip application. Am J Gastroenterol 2010; 105: 1447-1448

\section{Bibliography}

Dol http://dx.doi.org/

10.1055/s-0031-1291569

Endoscopy 2012; 44: E69-E70

(c) Georg Thieme Verlag KG

Stuttgart · New York

ISSN 0013-726X

\section{Corresponding author}

\section{Professor C. Li}

Gastrointestinal Endoscopy Center,

Sixth Affiliated Hospital of Sun Yat-sen University 26 Yuanchun Erheng Road

Guangzhou 510655

P. R. China

Fax: +86-20-38254221

lichujun@mail.sysu.edu.cn 